\title{
Hereditary haemorrhagic telangiectasia: a questionnaire based study to delineate the different phenotypes caused by endoglin and $A L K 1$ mutations
}

\author{
J Berg, M Porteous, D Reinhardt, C Gallione, S Holloway, T Umasunthar, A Lux, \\ W McKinnon, D Marchuk, A Guttmacher
}

See end of article for authors' affiliations

Correspondence to:

Correspondence to:
DrJ Berg, Department of Medical \& Molecular

Genetics, GKT School of Medicine, King's College London, 8th Floor Guy's

Tower, Guy's Hospital,

London SE 1 9RT, UK:

jonathan.berg@kcl.ac.uk

Revised version received 9 May 2003

Accepted for publication

9 May 2003
Background: Hereditary haemorrhagic telangiectasia (HHT) is an autosomal dominant vascular dysplasia characterised by mucocutaneous telangiectasis, epistaxis, gastrointestinal haemorrhage, and arteriovenous malformations in the lung and brain. Causative mutations for HHT have been identified in two genes, endoglin and $A L K 1$, which encode proteins involved in serine-threonine kinase signalling in the endothelial cell.

Methods: A number of people affected with HHT had completed a postal questionnaire as part of an international study to delineate the HHT phenotype. We identified questionnaires completed by subjects in whom we had identified a mutation in endoglin or $A L K 1$. Further questionnaires were sent to families with known mutations. Data were only included from questionnaires returned by people known to carry disease causing mutations.

Results: Questionnaires were completed by 83 subjects with known mutations. Of these, 49 had endoglin mutations (HHT1) and 34 had $A L K 1$ mutations (HHT2). Subjects with HHT1 reported an earlier onset of epistaxis $(p=0.01)$ and telangiectasis $(p=0.0001)$ than those with HHT2. Pulmonary arteriovenous malformations were only reported in the endoglin mutation group in our study $(p<0.001)$. Conclusions: Our questionnaire based study provides evidence that the HHT phenotype caused by mutations in endoglin (HHT1) is distinct from, and more severe than, HHT caused by mutations in ALK 1 (HHT2). This has significant implications for diagnosis, screening, and treatment in the two different forms of HHT, as well as for understanding the pathogenesis of the disease.
$\mathrm{H}$ ereditary haemorrhagic telangiectasia (HHT) is an autosomal dominant vascular dysplasia. Estimates of the incidence of HHT vary widely, but studies have shown that it affects between 1 in 8345 and 1 in 40000 people, with even higher incidence in some isolated populations. ${ }^{1-4}$ It is characterised by mucocutaneous telangiectases, most commonly affecting the tongue, lips, fingers, ears, and conjunctivae, in association with severe frequent epistaxis and gastrointestinal haemorrhage. A subset of subjects have pulmonary arteriovenous malformations (PAVMs) and cerebral arteriovenous malformations (CAVMs). ${ }^{5-7}$ Screening for PAVMs, which allows early detection and treatment of lesions, is thought to reduce the incidence of associated complications, including stroke, cerebral abscess, cardiac failure, and pulmonary haemorrhage. ${ }^{8}$ Complications of PAVMs are particularly likely to arise during pregnancy. ${ }^{9}$ An increased incidence of classical migraine has also been reported in HHT. ${ }^{10}$ Further complications of HHT include haemorrhage from gastrointestinal telangiectasis ${ }^{11}$ and hepatic arteriovenous malformations. ${ }^{12}{ }^{13}$ Gastrointestinal haemorrhage most commonly occurs after the age of $60 .^{11}$

Although HHT is highly penetrant, evidence of disease may not be present until after the age of $30 .^{23}$ Subjects at risk of inheriting a mutation may, therefore, require screening for PAVMs before definite assignment of affected status, and even after such screening may defy certain assignment of affected status.

Germline mutations which cause HHT have been identified in two genes, endoglin and $A L K 1 .{ }^{14-18}$

Endoglin is a TGF-beta binding protein, expressed in endothelial cells. ${ }^{19}$ Endoglin binds TGF-beta 1 and -beta 3, but not -beta 2. Endoglin also binds activin-A, BMP2, and BMP7. ${ }^{20} 21$ Endoglin has been shown to influence TGF-beta signalling in different in vitro assays. ${ }^{22}{ }^{23}$ Endoglin is also expressed, to some extent, in other cell types including syncytiotrophoblasts, activated monocytes, and other haematopoietic cells. ${ }^{24-28}$ Endoglin expression in specific cell types is increased in a number of disease processes, including expression in fibroblasts in scleroderma ${ }^{29}$ and in smooth muscle cells in atherosclerotic plaques. ${ }^{30}$

ALKl is a type 1 serine-threonine kinase receptor, expressed predominantly in endothelial cells. ${ }^{31}{ }^{32}$ ALK1 has been shown to bind TGF-beta $\mathrm{l}$ and activin-A in vitro, and can show signalling in response to either TGF-beta 1 or -beta 3. There may be a further unidentified ligand..$^{31}{ }^{33}$ ALKl has been shown to signal via phosphorylation of SMADl and SMAD5. ${ }^{34}{ }^{35}$

We have shown previously that subjects with known endoglin mutations have an incidence of pulmonary arteriovenous malformations of approximately $30 \%$, but that the incidence is less than $5 \%$ in subjects in whom the endoglin locus had been excluded. ${ }^{36}$ Two families that have been published with known ALKl mutations have shown PAVMs in some affected subjects, but in one family reported this was at a lower rate than in subjects with endoglin mutations. ${ }^{37}$ In the other family reported, HHT was caused by a specific missense mutation in $A L K l .^{38}$ No previous study has attempted a more detailed comparison of different clinical features between subjects with endoglin mutations and those with $A L K 1$ mutations.

In this study we compare clinical data from subjects with HHT with known endoglin mutations (HHT1) and subjects with HHT with known ALK1 mutations (HHT2). Our cohort consists of those in whom we have identified mutations as a part of previous and ongoing studies. Clinical data were obtained by questionnaire, either sent to people in the United Kingdom and the USA as a part of a world wide postal survey 
Table 1 The number of subjects and mutations identified in each family from which a person returned a questionnaire. Where a family has been published previously, the same family identification number is given as has been used in the previous article, and the source is given: $a$, McAllister et $a l_{1}{ }^{14} b$, McAllister ef $a l_{,}^{15} \mathrm{c}$, Gallione et $a l_{,}^{18} \mathrm{~d}$, Johnson et $a l_{1}^{16} \mathrm{e}$, Berg et al, ${ }^{17} \mathrm{f}$, previously unpublished data

\begin{tabular}{|c|c|c|c|c|}
\hline $\begin{array}{l}\text { Family } \\
\text { ID }\end{array}$ & Gene & $\begin{array}{l}\text { Mutation } \\
\text { identified }\end{array}$ & Mutation effect & $\begin{array}{l}\text { No of } \\
\text { subjects }\end{array}$ \\
\hline $1^{c}$ & Endoglin & $1311 \mathrm{G}>\mathrm{C}$ & Splice disruption & 11 \\
\hline $8^{c}$ & Endoglin & $155 \mathrm{G}>\mathrm{T}$ & G52V & 1 \\
\hline $32^{b}$ & Endoglin & $1414 C>T$ & Q472X & 3 \\
\hline $49^{a}$ & Endoglin & $831 C>G$ & Y277X & 2 \\
\hline $53^{b}$ & Endoglin & 1655 delC & Frameshift & 1 \\
\hline $56^{b}$ & Endoglin & $1050 T>A$ & C350X & 4 \\
\hline $58^{c}$ & Endoglin & 1432delAG & Frameshift & 5 \\
\hline $63^{a}$ & Endoglin & 1553delGC & Frameshift & 3 \\
\hline $73^{c}$ & Endoglin & $157 T>C$ & C53R & 6 \\
\hline $93^{c}$ & Endoglin & 1078delCAGA & Frameshift & 6 \\
\hline $139^{\circ}$ & Endoglin & $2 T>G$ & Abolish start & 1 \\
\hline $142^{c}$ & Endoglin & $447 G>C$ & W149C & 1 \\
\hline$A^{f}$ & Endoglin & $511 \mathrm{C}>\mathrm{T}$ & $\mathrm{R} 171 \mathrm{X}$ & 1 \\
\hline$B^{f}$ & Endoglin & 245 de $\mid \mathrm{T}>\mathrm{C}$ & Frameshift & 1 \\
\hline$C^{f}$ & Endoglin & $90 \mathrm{~T}>\mathrm{A}$ & C30X & 1 \\
\hline$D^{f}$ & Endoglin & IVS5+1,gt & Splice disruption & 1 \\
\hline$E^{f}$ & Endoglin & IVS3+1,gt & Splice disruption & 1 \\
\hline $17^{e}$ & ALKI & $865 \mathrm{ins} T$ & Frameshift & 1 \\
\hline $20^{e}$ & $A L K I$ & $998 \mathrm{G}>\mathrm{T}$ & S3331 & 1 \\
\hline $33^{d}$ & $A L K 1$ & $1127 \mathrm{~T}>\mathrm{G}$ & M376R & 1 \\
\hline $40^{d}$ & $A L K 1$ & $1232 G>A$ & R4 $11 Q$ & 7 \\
\hline $67^{d}$ & $A L K 1$ & 694delTCC & Del Ser 232 & 15 \\
\hline $92^{\mathrm{e}}$ & $A L K 1$ & $924 C>A$ & C308X & 3 \\
\hline $100^{\circ}$ & $A L K 1$ & $200 G>A$ & R67Q & 1 \\
\hline $\mathrm{Fe}^{\mathrm{e}}$ & $A L K 1$ & $150 G>T$ & W50C & 2 \\
\hline$G^{e}$ & $A L K 1$ & $1270 C>A$ & P424T & 3 \\
\hline
\end{tabular}

to define the HHT phenotype, or distributed to members of families with HHT caused by known mutations.

\section{METHODS}

\section{Subject selection and questionnaire administration}

This study was conducted with IRB approval from the University of Vermont, protocol No 650, "Hereditary haemorrhagic telangiectasia: its natural history and genotype-phenotype correlations", as well as IRB approval from Duke University.

The majority of subjects included in this study had been sent a self-administered questionnaire as a part of an international survey to define the HHT phenotype better. The questionnaire was distributed to people with a clinical diagnosis of HHT without reference to the results of mutation analysis. From records held, we identified those subjects in whom a mutation had been identified and selected the questionnaires that had been returned by these people. The same questionnaire was subsequently sent to members of families in whom a mutation had been identified. Clinical data about any subject were only included in the study when a sample had been received from that subject and presence of a mutation confirmed. This methodology did not allow us to count how many questionnaires had been received by a person with a known mutation and not returned.

The questionnaire inquired about general health as well as specific features of HHT. For all symptoms, presence or absence of the symptom was noted. Information on frequency, age of onset, and severity of symptoms was requested.

\section{Mutation analysis and assignment of affected status}

Subjects were only included if a mutation had been identified in previous studies or as a part of ongoing research. Mutations were identified by sequencing of endoglin and $A L K 1$ as previously described..$^{14-18}$
Table 2 Proportion of males and females, with mean (SD) age, for the HHT1 and HHT2 groups

\begin{tabular}{llllll}
\hline Gene & $\begin{array}{l}\text { No of } \\
\text { subjects }\end{array}$ & $\begin{array}{l}\text { No of } \\
\text { males }\end{array}$ & $\begin{array}{l}\text { Mean age } \\
\text { of males }\end{array}$ & $\begin{array}{l}\text { No of } \\
\text { females }\end{array}$ & $\begin{array}{l}\text { Mean age } \\
\text { of females }\end{array}$ \\
\hline Endoglin & 49 & $21(43 \%)$ & $48.0(15.3)$ & $28(57 \%)$ & $46.5(11.9)$ \\
ALK1 & 34 & $14(41 \%)$ & $51.3(24.1)$ & $20(59 \%)$ & $65.3(19.9)$ \\
\hline
\end{tabular}

\section{Data analysis}

Questionnaire data were collected on the following features: presence and age of onset of epistaxis, presence and age of onset of telangiectasis, symptoms suggestive of gastrointestinal haemorrhage, presence of PAVMs (diagnosed by a physician), presence of CAVMs (diagnosed by a physician), history of miscarriage, and symptoms of classical migraine. Symptoms of classical migraine were taken to be present when a person described symptoms of visual disturbance followed by headache. For each person with an identified mutation who returned a questionnaire, clinical data were entered on a Microsoft Access $97^{\mathrm{TM}}$ database. Mutation data were entered into the same database for each person. The proportion of subjects in each mutation group with each complication was calculated. Groups were compared using $2 \times 2$ table analysis with either the chi-square test or Fisher's exact test. The $\mathrm{p}$ values for individual tests were multiplied by the number of comparisons made, to compensate for multiple testing (Bonferroni method).

To compare age of onset of epistaxis and age of first appearance of telangiectases in subjects with endoglin and ALKI mutations, Kaplan-Meier survival curves were plotted, and the logrank test used to compare subjects in the two groups.

\section{RESULTS}

Questionnaires were completed by 83 subjects with known mutations. Of these, 49 had endoglin mutations (HHTl) and 34 had ALK1 mutations (HHT2). This sample set is only a small proportion of the people affected with HHT in the UK and USA, because we chose only to include those patients in whom a confirmed pathogenic mutation had already been identified. Details of the type of mutation identified, the number of subjects with each mutation, and source of the original mutation data, are given in table 1. Numbers, percentages, and mean (SD) ages of males and females within each group are given in table 2 . There was no significant difference between the proportion of males and females in the HHT1 and HHT2 groups. The mean age of females with HHT2 who returned questionnaires was significantly $(p=0.001)$ higher than the mean age of the females in the other group. There was no significant difference between the mean age of males in the two groups.

The proportion of subjects affected with each feature of HHT is given in table 3. In this analysis we have found a reported incidence of PAVMs, in subjects with HHT1, of 35\%. This agrees with previous estimates. We found a much lower incidence of PAVM in those with HHT2 $(0 \%$ in this study, $\mathrm{p}<0.001)$.

No significant differences were seen between the HHTl and HHT2 groups for the proportion of subjects affected with CAVMs, gastrointestinal haemorrhage, or history of miscarriage in women aged over 16 . Only two subjects in each group reported hepatic involvement.

More people with HHTl reported a CAVM (4/49) than those with HHT2 (1/34), but the numbers in both groups were small. Symptoms suggestive of migraine were also reported more frequently in HHTl (20/49) than HHT2 (6/34); however, this difference was not significant after correction for multiple testing. Gastrointestinal bleeding after the age of 60 was 
Table 3 A comparison of the HHT1 and HHT2 groups looking at the presence or absence of disease features

\begin{tabular}{llll}
\hline Feature & $\begin{array}{l}\text { Endoglin } \\
\text { mutation }\end{array}$ & $\begin{array}{l}\text { ALK1 } \\
\text { mutation }\end{array}$ & Significance \\
\hline Epistaxis & $48 / 49$ & $34 / 34$ & NS \\
Telangiectasis & $47 / 49$ & $28 / 34$ & NS \\
Pulmonary arteriovenous malformation (PAVM) & $17 / 49$ & $0 / 34$ & p<0.001 \\
Cerebral arteriovenous malformation (CAVM) & $4 / 49$ & $1 / 34$ & NS \\
Gastrointestinal haemorrhage & $6 / 49$ & $9 / 34$ & NS \\
Gastrointestinal haemorrhage (age 60+) & $1 / 9$ & $7 / 19$ & NS \\
Miscarriage in affected female (age 16+) & $8 / 28$ & $8 / 20$ & NS \\
Symptoms suggestive of classical migraine & $20 / 49$ & $6 / 34$ & NS \\
\hline
\end{tabular}

reported less frequently in HHTl (affecting 1/9 subjects) than in HHT2 (affecting 7/19 subjects), but this finding did not achieve significance. The average age of females in the HHT2 group was greater than the average age in the HHTl group. As
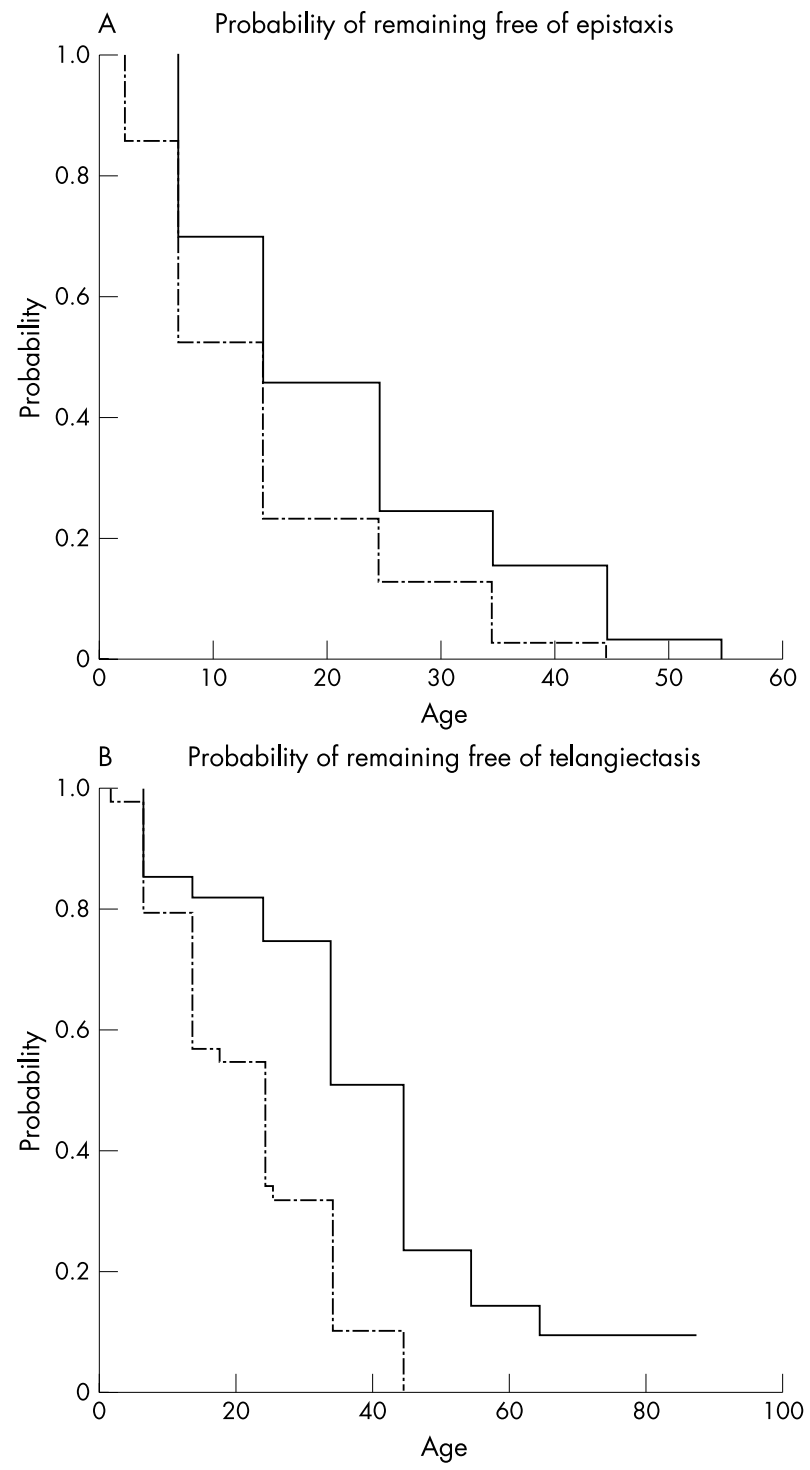

Figure 1 Kaplan-Meier survival curves showing probability of remaining symptom free for (A) epistaxis and (B) telangiectasis. The curves for subjects with $\mathrm{HHTl}$ are given as the interrupted line and for subjects with HHT2 as the continuous line. For both epistaxis $(p=0.01)$ and telangiectasis $(p=0.0001)$, the age of onset of symptoms is significantly younger in subjects with $\mathrm{HHTl}$. gastrointestinal bleeding is more common in the elderly, this may account for the greater number of subjects affected with gastrointestinal bleeding in the HHT2 group.

Most subjects had a history of epistaxis and telangiectasia at the time of completion of the questionnaire. We therefore compared age of onset of these features between the HHTl and HHT2 groups. Kaplan-Meier survival curves are shown in fig 1 for age of onset of epistaxes and of first appearance of telangiectases. For both of these clinical features the logrank test showed a significant difference between the survival curves for the two mutation groups: epistaxes $(p=0.01)$ and telangiectases $(p=0.0001)$. In both cases subjects with HHTl had earlier onset of symptoms. Further logrank tests were carried out where the survival distributions were adjusted for sex differences, and the significance levels remained the same. The proportion of subjects developing these symptoms by a given age, estimated from the curves, is shown in table 4 .

\section{DISCUSSION}

This is the first study of HHT to compare subjects with known endoglin mutations and those with known ALKl mutations for a range of clinical features. This study identifies a distinct difference in phenotype between people with endoglin mutations (HHTl) and those with ALK1 mutations (HHT2). Subjects with HHTl and those with HHT2 both have epistaxis, telangiectasis, and gastrointestinal haemorrhage. However, subjects with HHTl have significantly earlier onset of epistaxis and telangiectasis. Overall, HHTl has a more severe phenotype than HHT2

As HHT is a comparatively rare disease, the use of a questionnaire is an efficient and practical method for obtaining data from a cohort of subjects across a large geographical area. However, a significant limitation of this study is that, for practical reasons, clinical data were collected solely by questionnaire, without confirmation of events from medical records. As a number of subjects were not formally screened for internal vascular malformations, especially PAVMs or

Table 4 Proportion of subjects showing epistaxis or telangiectasis by a given age

\begin{tabular}{llllll}
\hline \multicolumn{3}{l}{ Endoglin mutation } & & \multicolumn{2}{l}{ ALK1 mutation } \\
\cline { 1 - 2 } \cline { 5 - 6 } Age & Epistaxis & Telangiectasis & & Epistaxis & Telangiectasis \\
\hline 4 & 0.15 & 0.02 & 0.0 & 0.0 \\
9 & 0.48 & 0.21 & 0.30 & 0.14 \\
19 & 0.77 & 0.46 & 0.55 & 0.18 \\
29 & 0.88 & 0.68 & 0.76 & 0.26 \\
39 & 0.98 & 0.90 & 0.85 & 0.49 \\
49 & 1.0 & 1.0 & 0.97 & 0.77 \\
59 & 1.0 & 1.0 & 1.0 & 0.86 \\
69 & 1.0 & 1.0 & 1.0 & 0.91 \\
\hline
\end{tabular}


CAVMs, there will be significant under-reporting of these lesions in both the HHTl and HHT2 groups. As patients who present to medical services are likely to be more severely affected, frequency and severity of epistaxis and telangiectasis are probably over-reported in both groups. However, we feel that these factors are likely to have affected both cohorts fairly equally, and that comparison between the groups remains valid.

There will be differences in screening protocols, and these differences are likely to be particularly marked between subjects from the USA and those from other areas. Screening protocols, particularly those for PAVMs, do vary in their sensitivity and specificity, and the questionnaire was not able to identify which protocol was used to screen each subject. However, the majority of people from both the HHTl and HHT2 cohorts were from the USA, so we do not feel that difference in screening protocols is a significant source of bias in determining the difference between HHTl and HHT2 groups. The variation in quality of screening offered will, however, reduce the number of lesions reported in both groups.

The proportions of males and females in the HHTl and HHT2 groups were the same, which is important, as oestrogen levels can affect endothelial cell function. Oestrogens are also used to treat gastrointestinal bleeding in HHT. The higher average age of females in the HHT2 group is likely, if it has any effect, to lead to understatement of the difference between the HHTl and HHT2 groups, as older subjects would have had longer to manifest signs of disease or suffer complications from PAVMs or CAVMs. We do not think, therefore, that this age difference will have led to a significant bias in our results.

In this study, PAVMs were identified only in subjects with HHTl; $35 \%$ of those with HHTl who returned a questionnaire reported a PAVM. The cohort in this study overlaps with that previously reported. ${ }^{36}$ The collection of clinical data for this study was, however, independent of the previous survey.

While the difference in frequency of gastrointestinal (GI) haemorrhage between the groups did not achieve statistical significance, a larger proportion of subjects with HHT2 over the age of 60 had symptoms of GI haemorrhage (7/19) compared to those with HHTI (1/9). While this may also be caused by earlier mortality of HHTl patients who have GI haemorrhage, there may be a genuine difference in phenotype, with subjects with HHT2 being more prone to GI telangiectasis.

\section{Do phenotypic differences provide information about the signalling pathways for ALK1 and endoglin in the endothelial cell?}

The fact that HHT1 and HHT2 share most of their phenotypic features suggests that endoglin and ALKl share a common signalling pathway in the endothelial cell. They may interact directly at the cell surface, or their signalling pathways may converge within the cell. Interaction of endoglin with ALKI has been shown in vitro. ${ }^{33}{ }^{39}$ Ligand binding assays in COS cells showed a TGF-beta 1 and -beta 3 dependent endoglin/ALKl/ TGF-beta receptor II complex. ${ }^{39}$

Greater severity of HHTl may suggest that endoglin has an extra signalling role in addition to the pathway it shares with ALKl. Evidence for this comes from Barbara et al, ${ }^{21}$ who have shown that endoglin can bind activin-A, BMP2, and BMP7 when co-expressed in vitro with different serine threonine kinase receptors. In addition, although endoglin and $A L K 1$ knockout mice show similar phenotypes and are embryo lethal around E10.5 owing to defects in angiogenesis, there is a major difference in the vascular morphology of the embryo proper at E9.5. ${ }^{40}$ Zwijsen $e t ~ a l^{40}$ suggest that endoglin plays a role in both the ALK1 and the TGF-beta receptor type I (ALK5) pathway. Endoglin has also been shown to interact directly with the TGF-beta receptor type $1 .{ }^{41}$ Therefore, mutations in endoglin would disrupt both ALKl and ALK5 signalling, whereas mutations in $A L K 1$ would lead to a dominance of ALK5 mediated effects.

It is possible that the presence of other type I serine threonine kinase receptors in the endothelial cell that also signal through SMADI/SMAD5 (including the bone morphogenic protein receptors) may also compensate for ALKl deficiency, leading to a less severe phenotype in HHT2.

\section{Clinical implications for the difference between HHT 1 and HHT2}

Clinical differences between HHTI and HHT2 have important implications for the diagnosis and management of HHT. Although data collected by questionnaire should be used with caution, these clinical data will be useful in genetic counselling of subjects, providing a clearer picture of disease, both for those affected and for those considering presymptomatic testing. Although no PAVM was reported in a subject with an ALKI mutation in our study, it is important to note that two papers have reported PAVMs in HHT2 families, although usually at lower frequency than in HHTl families. $^{3638}$ Therefore, all subjects with HHT should, at present, be offered pulmonary screening for PAVMs. Subjects with HHTl represent a particularly high risk group, although further investigation is required to identify whether people with HHTl or HHT2 merit different screening protocols. In the absence of a known mutation in a family with HHT, a family history of PAVM is suggestive of HHTl rather than HHT2, and this information can be used to target mutation analysis more efficiently.

Our study is not large enough to identify differences in clinical features caused by different types of mutation at one locus. For example, do missense mutations have a more severe phenotype than null mutations? Only a study of a larger number of subjects with known mutations can answer such questions.

Seventy-seven percent of those with HHTl reported onset of nosebleeds before the age of 20 , and $88 \%$ before the age of 30 , so in this group at risk relatives without this symptom after the age of 30 are less likely to be affected. The later onset of classical symptoms in HHT2, with only 55\% showing epistaxis before the age of 20 and $76 \%$ before the age of 30, suggests that some subjects with HHT2 will not manifest sufficient clinical features for a diagnosis of HHT until their third or fourth decade of life. In the absence of mutation testing, it is therefore important to maintain clinical surveillance of those at risk of inheriting a HHT mutation, at least until the age of 40, if not longer. Genetic testing for HHT, where available, will be essential to allow targeting of surveillance and screening to only those who have a mutation.

We conclude that knowing which locus is mutated is important for the accurate genetic counselling of subjects with HHT. The difference in frequency and age of onset of different complications of HHT suggests that future clinical studies of the disease will only be valid if they take into account the locus involved. Large genotype-phenotype studies, including confirmation of details from medical records or a detailed, consistent investigation protocol for each patient, are required to investigate whether there are genuine differences in the frequency of GI haemorrhage, cerebral arteriovenous malformations, and migraine between HHT1 and HHT2. Such investigations will also be able to confirm and quantify more accurately the significant differences that we have observed in our study for epistaxis, telangiectasis, and pulmonary arteriovenous malformations.

The differences between HHTl and HHT2 patients will also be an important consideration in therapeutic trials for patients with HHT, as the locus involved may have a profound influence on response to treatments targeted to specific signalling pathways. 


\section{ACKNOWLEDGEMENTS}

This work was funded by a Mrs Jean V Baxter Medical Research Fellowship awarded by the Scottish Hospital Endowment Research Trust to JNB, NIH Grant HL49171 to DAM, and a Wellcome Biomedical Research Collaboration Grant to MEMP and DAM. We would also like to thank the many clinicians who helped develop the natural history questionnaire, the families who participated in the research, and the HHT Foundation International for their support.

\section{Authors' affiliations}

J Berg, Department of Medical and Molecular Genetics, GKT School of Medicine, King's College London, 8th Floor, Guy's Tower, Guy's Hospital, London SE 1 9RT, UK and Department of Molecular and Cellular Pathology, Ninewells Hospital and Medical School, Dundee DD1 9SY, UK

M Porteous, S Holloway, T Umasunthar, South-East Scotland Regional Genetics Service, Molecular Medicine Centre, Western General Hospital, Crewe Road, Edinburgh EH4 2XU, UK

D Reinhardt, MRC Human Genetics Unit, Western General Hospital, Crewe Road, Edinburgh EH4 2XU, UK

C Gallione, D Marchuk, Department of Genetics, Duke University Medical Center, Durham, NC 27710, USA

A Lux, University Clinics, Mannheim University of Heidelberg and Institute of Molecular Biology and Cell Culture Technology, University of Applied Science, Mannheim, Windeckstrasse 1 10, 68163 Mannheim, Germany

W McKinnon, Vermont Regional Genetics Center, University of Vermont College of Medicine, Burlington, VT 05401, USA

A Guttmacher, National Human Genome Research Institute, National Institutes of Health, Bethesda, MD 20892, USA

\section{REFERENCES}

I Bideau A, Plauchu H, Jacquard A, Robert JM, Desjardins B. Genetic aspects of Rendu-Osler disease in Haut-Jura: convergence of methodological approaches of historic demography and medical genetics. J Genet Hum 1980;28: 127-47.

2 Plauchu $\mathbf{H}$, de Chadarevian JP, Bideau A, Robert JM. Age-related clinical profile of hereditary hemorrhagic telangiectasia in an epidemiologically recruited population. Am J Med Genet 1989;32:291-7.

3 Porteous ME, Burn J, Proctor SJ. Hereditary haemorrhagic telangiectasia: a clinical analysis. J Med Genet 1992;29:527-30.

4 Guttmacher AE, McKinnon WC, Upton MD. Hereditary hemorrhagic telangiectasia: a disorder in search of the genetics community. Am J Med Genet 1994;52:252-3.

5 Guttmacher AE, Marchuk DA, White RI Jr. Hereditary hemorrhagic telangiectasia. N Engl J Med 1995;333:918-24.

6 Vase $\mathbf{P}$, Holm M, Arendrup H. Pulmonary arteriovenous fistulas in hereditary hemorrhagic telangiectasia. Acta Med Scand 1985;218:105-9.

7 Maher CO, Piepgras DG, Brown RD Jr, Friedman JA, Pollock BE. Cerebrovascular manifestations in 321 cases of hereditary hemorrhagic telangiectasia. Stroke 2001;32:877-82

8 Dutton JA, Jackson JE, Hughes JM, Whyte MK, Peters AM, Ussov W, Allison DJ. Pulmonary arteriovenous malformations: results of treatment with coil embolization in 53 patients. Am J Roentgenol 1995; 165: $1119-25$.

9 Shovlin CL, Winstock AR, Peters AM, Jackson JE, Hughes JM. Medical complications of pregnancy in hereditary haemorrhagic telangiectasia. $Q$ J Med 1995:8:879-87.

10 Steele JG, Nath PU, Burn J, Porteous ME. An association between migrainous aura and hereditary haemorrhagic telangiectasia. Headache 1993;33:145-8.

11 Kjeldsen AD, Kjeldsen J. Gastrointestinal bleeding in patients with hereditary hemorrhagic telangiectasia. Am J Gastroenterol 2000;95:415-18

12 Garcia-Tsao G, Korzenik JR, Young L, Henderson KJ, Jain D, Byrd B, Pollak JS, White RI Jr. Liver disease in patients with hereditary hemorrhagic telangiectasia. N Engl J Med 2000;343:931-6.

13 Buscarini E, Buscarini L, Danesino C, Piantanida M, Civardi G, Quaretti $P$, Rossi S, Di Stasi M, Silva M. Hepatic vascular malformations in hereditary hemorrhagic telangiectasia: Doppler sonographic screening in a large family. J Hepatol 1997;26:111-18.

14 McAllister KA, Grogg KM, Johnson DW, Gallione CJ, Baldwin MA Jackson CE, Helmbold EA, Markel DS, McKinnon WC, Murrell J, McCormick MK, Pericak-Vance MA, Heutink P, Oostra BA, Haitjeman T, Westerman CJJ, Porteous ME, Guttmacher AE, Letarte M, Marchuk DA. Endoglin, a TGF-beta binding protein of endothelial cells, is the gene for hereditary haemorrhagic telangiectasia type 1. Nat Genet 1994:8:345-51.

15 McAllister KA, Baldwin MA, Thukkani AK, Gallione CJ, Berg JN, Porteous ME, Guttmacher AE, Marchuk DA. Six novel mutations in the endoglin gene in hereditary hemorrhagic telangiectasia type 1 suggest a dominant-negative effect of receptor function. Hum Mol Genet 1995;4:1983-5.
16 Johnson DW, Berg JN, Baldwin MA, Gallione CJ, Marondel I, Yoon SJ, Stenzel TT, Speer M, Pericak-Vance MA, Diamond A, Guttmacher AE, Jackson CE, Attisano L, Kucherlapati R, Porteous ME, Marchuk DA. Mutations in the activin receptor-like kinase 1 gene in hereditary haemorrhagic telangiectasia type 2. Nat Genet 1996;13:189-95.

17 Berg JN, Gallione CJ, Stenzel TT, Johnson DW, Allen WP, Schwartz CE, Jackson CE, Porteous ME, Marchuk DA. The activin receptor-like kinase 1 gene: genomic structure and mutations in hereditary hemorrhagic telangiectasia type 2. Am J Hum Genet 1997;61:60-7

18 Gallione CJ, Klaus DJ, Yeh EY, Stenzel TT, Xue Y, Anthony KB, McAllister KA, Baldwin MA, Berg JN, Lux A, Smith JD, Vary CP, Craigen WJ, Westermann CJ, Warner ML, Miller YE, Jackson CE, Guttmacher AE, Marchuk DA. Mutation and expression analysis of the endoglin gene in hereditary hemorrhagic telangiectasia reveals null alleles. Hum Mutat 1998;11:286-94.

19 Gougos A, Letarte M. Primary structure of endoglin, an RGD-containing glycoprotein of human endothelial cells. J Biol Chem 1990;265:8361-4.

20 Cheifetz S, Bellon T, Cales C, Vera S, Bernabeu C, Massague J, Letarte $M$. Endoglin is a component of the transforming growth factor-beta receptor system in human endothelial cells. J Biol Chem 1992;267: 19027-30

21 Barbara NP, Wrana JL, Letarte M. Endoglin is an accessory protein that interacts with the signaling receptor complex of multiple members of the transforming growth factor-beta superfamily. J Biol Chem 1999;274:584-94.

22 Letamendia A, Lastres P, Botella LM, Raab U, Langa C, Velasco B, Attisano L, Bernabeu C. Role of endoglin in cellular responses to transforming growth factor - a comparative study with betaglycan. J Biol Chem 1998;273:330119.

23 Li C, Hampson IN, Hampson L, Kumar P, Bernabeu C, Kumar S. CD105 antagonizes the inhibitory signaling of transforming growth factor betal on human vascular endothelial cells. FASEB J 2000;14:55-64.

24 Lastres P, Bellon T, Cabanas C, Sanchez-Madrid F, Acevedo A, Gougos A, Letarte $M$, Bernabeu C. Regulated expression on human macrophages of endoglin, an Arg-Gly-Asp-containing surface antigen. Eur J Immunol 1992;22:393-7.

25 Caniggia I, Taylor CV, Ritchie JW, Lye SJ, Letarte M. Endoglin regulates trophoblast differentiation along the invasive pathway in human placental villous explants. Endocrinology 1997; 138:4977-88.

26 Adam PJ, Clesham GJ, Weissberg PL. Expression of endoglin mRNA and protein in human vascular smooth muscle cells. Biochem Biophys Res Commun 1998;247:33-7.

27 Guerrero-Esteo $M$, Lastres $P$, Letamendia A, Perez-Alvarez $M$, Langa C, Lopez LA, Fabra A, Garcia-Pardo A, Vera S, Letarte M, Bernabeu C. Endoglin overexpression modulates cellular morphology, migration, and adhesion of mouse fibroblasts. Eur J Cell Biol 1999;78:614-23.

28 Ma X, Labinaz M, Goldstein J, Miller H, Keon WJ, Letarte M, O’Brien E. Endoglin is over-expressed after arterial injury and is required for transforming growth factor-beta-induced inhibition of smooth muscle cell migration. Arterioscler Thromb Vasc Biol 2000;20:2546-52.

29 Leask A, Abraham DJ, Finlay DR, Holmes A, Pennington D, Shi-Wen X, Chen Y, Venstrom K, Dou X, Ponticos M, Black C, Bernabeu C, Jackman JK, Findell PR, Connolly MK. Dysregulation of transforming growth factor beta signaling in scleroderma: overexpression of endoglin in cutaneous scleroderma fibroblasts. Arthritis Rheum 2002;46:1857-65.

30 Conley BA, Smith JD, Guerrero-Esteo M, Bernabeu C, Vary CP. Endoglin, a TGF-beta receptor-associated protein, is expressed by smooth muscle cells in human atherosclerotic plaques. Atherosclerosis 2000; 153:323-35

31 Attisano L, Carcamo J, Ventura F, Weis FM, Massague J, Wrana J. Identification of human activin and TGF beta type I receptors that form heteromeric kinase complexes with type II receptors. Cell 1993;75:671-80

32 ten Dijke P, Ichijo H, Franzen P, Schulz P, Saras J, Toyoshima H, Heldin $\mathrm{CH}$, Miyazono K. Activin receptor-like kinases: a novel subclass of cell-surface receptors with predicted serine/threonine kinase activity. Oncogene 1993;8:2879-87.

33 Lux A, Attisano L, Marchuk DA. Assignment of transforming growth factor beta 1 and beta3 and a third new ligand to the type I recepto ALK-1. J Biol Chem 1999:274:9984-92.

34 Macias-Silva M, Hoodless PA, Tang SJ, Buchwald M, Wrana JL. Specific activation of Smad 1 signaling pathways by the BMP7 type receptor, ALK2. J Biol Chem 1998;273:25628-36.

35 Chen YG, Massague J. Smad 1 recognition and activation by the ALK 1 group of transforming growth factor-beta family receptors. J Biol Chem 1999:274:3672-7.

36 Berg JN, Guttmacher AE, Marchuk DA, Porteous ME. Clinica heterogeneity in hereditary haemorrhagic telangiectasia: are pulmonary arteriovenous malformations more common in families linked to endoglin? J Med Genet 1996:33:256-7.

37 McDonald JE, Miller FJ, Hallam SE, Nelson L, Marchuk DA, Ward KJ. Clinical manifestations in a large hereditary hemorrhagic telangiectasia (HHT) type 2 kindred. Am J Med Genet 2000;93:320-7.

38 Kjeldsen AD, Brusgaard K, Poulsen L, Kruse T, Rasmussen K, Green A, Vase P. Mutations in the ALK-1 gene and the phenotype of hereditary hemorrhagic telangiectasia in two large Danish families. Am J Med Genet 2000;98:298-302.

39 Abdalla SA, Pece-Barbara N, Vera S, Tapia E, Paez E, Bernabeu C Letarte M. Analysis of ALK-1 and endoglin in newborns from families with hereditary hemorrhagic telangiectasia type 2. Hum Mol Genet 2000;9:1227-37.

40 Zwiijsen A, van Grunsven LA, Bosman EA, Collart C, Nelles L, Umans L, Van de Putte T, Wuytens G, Huylebroeck D, Verschueren K. Transforming 
growth factor beta signalling in-vitro and in vivo: activin ligand-receptor interaction, Smad5 in vasculogenesis, and repression of target genes by the deltaEF 1 /ZEB-related SIP1 in the vertebrate embryo. Mol Cell Endocrinol 2001:180:13-24.
41 Guerrero-Esteo $M$, Sanchez-Elsner T, Letamendia A, Bernabeu $C$ Extracellular and cytoplasmic domains of endoglin interact with the transforming growth factor- $\beta$ receptors I and II. J Biol Chem 2002:277:29197-29209.

\section{$\mathrm{ECHO}$}

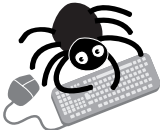

Please visit the Journal of Medical

Genetics website [www.jmedgenet. com] for link to this full article.
Doctors get closer to deciding the true birth prevalence of Prader-Willi syndrome

more reliable estimate of the prevalence of Prader-Willi syndrome in Australian babies
is now available, following the first population study to assess genetically proven cases.

The birth prevalence of 4/100 000 live births (95\% confidence interval 2.7 to 5.7 ) or 1/25 000 live births /year is based on 30 notified cases between January 1998 and December 2000 in children aged under 1 year. It is a minimum estimate because of the possibility of missing data for the target age and failure to recognise cases clinically.

The 30 cases $(71 \%)$ were among 42 cases in children aged under 15 years, all confirmed by DNA methylation, fluorescent in situ hybridisation, or DNA polymorphisms. A paternal deletion on chromosome $15 q(11-13)$ was the cause in $21(70 \%)$ of the 30 cases and disomy in one parent in three $(10 \%)$ but was unknown in six.

The results were based on notifications to the Australian Paediatric Surveillance Unit. Paediatricians and child health specialists were asked to report newly diagnosed cases, whether on clinical or genetic criteria, in the past month in children aged under 15 . They were sent a copy of clinical diagnostic criteria and asked for demographic data, growth and genetic test results, perinatal and neonatal histories, and clinical details. Data on children aged under 1 year were used. The Australian Bureau of Statistics provided data on live births.

Prader-Willi syndrome is not always recognised, so is underestimated among babies and overestimated among obese retarded teenagers, and all previous estimates of prevalence have been retrospective.

A Archives of Disease in Childhood 2003;88:263-264

\section{SPINK1 mutations predispose to chronic pancreatitis}

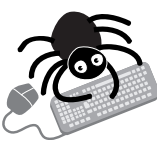

Please visit the Journal of Medical Genetics website [www. jmedgenet.com for link to this full article.
There is a high prevalence of serine protease inhibitor Kazal type l (SPINK1) mutations, not only in chronic idiopathic, but also alcoholic pancreatitis, with around one in eight patients affected, finds Dutch research. The findings are based on mutational analysis of 115 adult patients with alcoholic $(n=72)$, hereditary $(n=10)$, idiopathic $(n=24)$ and miscellaneous origin $(n=9)$ chronic pancreatitis.

The research team looked for two mutations in the PRSSI gene- $\mathrm{R} 122 \mathrm{H}$ and N291- and four specific mutations in the SPINKI gene-MIT, L14P, N34S and P55S-and compared the results with those from a group of 120 healthy adults.

The prevalence of SPINKl mutations was $12.2 \%$ among patients with alcoholic and idiopathic pancreatitis, and seven times higher than among the comparison group. In 13 out of the 14 cases, the most common variant was the N34S mutation, but two patients carried the P55S allele, one as a compound heterozygote with N34S. Just two people in the comparison group carried the N34S mutation.

PRSS 1 mutations were found in six out of 10 patients with hereditary pancreatitis and were associated with earlier disease onset than the N34S allele.

There are around 50 to 75 cases of chronic pancreatitis per 100000 of the population, with one in two people dying from their disease 20 years after diagnosis. Alcohol misuse accounts for up to $70 \%$ of cases in the West, but the authors conclude that SPINKI mutations are an important predisposing factor in the development of the disease.

A Gut 2002;50:687-692. 